\title{
Breve histórico da psiquiatria no Brasil: do período colonial à atualidade
}

\author{
Brief history of psychiatry in Brazil: from the colonial period \\ to the present
}

\author{
Luiz Salvador de Miranda-Sá Jr.
}

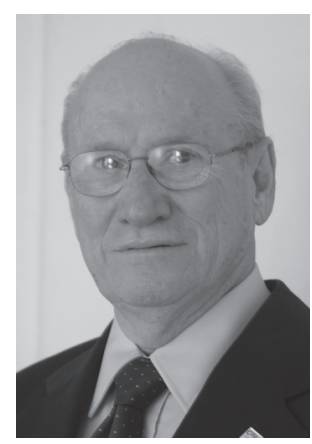

Sob a designação de psiquiatria incluem-se três tipos de conceitos diversos, apesar de correlacionados: a assistência, o conhecimento e o ensino do conhecimento psiquiátrico. Como não é possível abarcar todo esse universo, trataremos aqui e agora apenas de um aspecto do primeiro conceito: a assistência psiquiátrica pública.

A assistência aos doentes no Brasil colonial era extremamente precária. A maior parte dos cuidados era prestada por curandeiros de todos os matizes, inclusive sacerdotes católicos (especialmente os jesuítas). Os médicos formados eram raríssimos, e mesmo os cirurgiões e barbeiros licenciados dificilmente eram encontrados, a não ser nos centros maiores, e serviam principalmente as pessoas importantes. Não havia especialistas em psiquiatria, mas os hospitais da Irmandade da Santa Casa abrigavam, mais que tratavam, os enfermos mais necessitados. Sem casa e sem recursos - ou sem eira e sem beira, como se dizia na época. Sem eira porque não tinham propriedades rurais, nem beira, ou uma casa, um telhado com beiral sob o qual pudessem viver. Os mais pobres de todos não tinham onde cair mortos, ou seja, não tinham um túmulo em uma igreja onde pudessem ser sepultados para fugir à vala comum. Os enterros "decentes" só começaram a ser feitos fora das igrejas no século XIX. Os hospitais, até o século XVIII, confundiam-se com albergues para pessoas doentes que não tivessem quem cuidasse delas. Os hospitais das Irmandades das Santas Casas de Misericórdia acolhiam e albergavam esses doentes em condições sanitárias muito más, mesmo para aquele momento histórico-social.

Foi entre o fim do século XVIII e início do XIX, com o avanço do conhecimento científico e da consciência social, que a medicina começou a tomar a forma atual. A Revolução Francesa, no plano político, e os avanços científicos relacionados com a Revolução Industrial, no plano econômico, foram as influências mais significativas desse processo. Foi quando a assistência aos doentes mentais se tornou médica. Surgiu na França, com a reforma patrocinada por Pinel e instituída por Esquirol, e que serviu de modelo para as transformações na assistência psiquiátrica de todo o mundo ocidental. Foi quando a assistência aos doentes mentais se transformou em responsabilidade médica e estatal. No Brasil, também foi aí que nasceu a assistência psiquiátrica pública, já reformada segundo os valores da época.

O Brasil sofrera grandes transformações socioeconômicas e políticas. A corte portuguesa se mudara apressadamente para o Rio de Janeiro, tangida pela invasão das tropas napoleônicas; o país deixara de ser colônia e fora transformado em reino unido com Portugal e Algarve, o que representou uma enorme promoção em seu status político. A abertura dos portos, o fim da proibição de atividades econômicas e educacionais que havia caracterizado o regime colonial dera origem a uma nova situação econômica, cultural e política. A Independência, a superação da monarquia absoluta e a adesão ao liberalismo econômico marcaram esse momento e se refletiram em todos os aspectos da vida nacional - inclusive na assistência psiquiátrica.

O início da urbanização, premissa e conseqüência dessa transformação, mudou a fisionomia do Rio de Janeiro, de Ouro Preto e Salvador (únicas cidades brasileiras dignas de serem consideradas "urbanizadas") e, por outro lado, criou, ampliou e expôs novos problemas sanitários. Um deles dizia respeito aos enfermos psiquiátricos, que, se eram inoperantes nas pequenas comunidades rurais, tornavam-se visíveis e perturbadores no meio urbano. Cuidar deles se transformou em um ônus difícil de ser suportado até pelas famílias, tanto no plano objetivo como no subjetivo.

O Hospício do Rio de Janeiro foi inaugurado como parte da comemoração da Declaração da 
Maioridade do Imperador Pedro II e já nasceu moderno, pois seguiu o recém-instituído modelo francês e serviu de paradigma para os demais que o seguiram. Era um estabelecimento médico voltado para a recuperação dos doentes. O Hospício do Rio hoje é utilizado como Reitoria da UFRJ. Trata-se de um palácio mais suntuoso que qualquer outro da época, mais que o Palácio Real da Praça Quinze ou o de São Cristóvão, tendo sido equiparado pelo Palácio Guanabara, edificado para servir de morada a D. Isabel, princesa herdeira, quando de seu casamento, muitos anos após. Coisa semelhante se deu nas províncias. A exemplo do caso do Rio, muitos desses hospitais eram palácios maravilhosos para a época.

Esses são os fatos acerca das enfermidades mentais graves que, curiosamente, deram origem a duas interpretações opostas. Os historiadores otimistas os explicam como sendo fruto da caridade cristã, do desejo de minorar o sofrimento alheio, de solidarizarse com quem padece uma doença que todos temem. Os pessimistas, por sua vez, atribuem-nos ao desejo de esconder a miséria e a loucura, de aumentar o sofrimento do sofredor. Provavelmente, ambos têm parte da verdade.

A despeito dos prédios majestosos, a falta de recursos eficazes para o tratamento dos doentes e a pobreza de sua clientela determinaram sua progressiva deterioração e declínio, ainda que o aumento da população enferma exigisse a expansão do sistema, com a ampliação de suas unidades. Entre os anos 20 e 30 do século XX, deu-se o primeiro esforço de reforma: Juliano Moreira e Ulisses Pernambucano foram os primeiros artífices. Ulisses diferenciou os serviços de psicóticos agudos dos crônicos, instituiu um serviço aberto para tratamento em regime de pensão livre, criou um sistema de educação especial e um serviço de saúde mental. Mas não viveu o bastante para ver prosperar sua obra nem para assistir à degradação de sua criação.

À medida que a falta de remédios específicos para os enfermos psiquiátricos continuava, o processo de degradação da assistência psiquiátrica pública no Brasil, tal como no resto do mundo, prosseguia e se aprofundava. A degradação só poderia ser detida com a descoberta dos fármacos psicotrópicos, que possibilitaram o efetivo enfrentamento das enfermidades mentais. Foi a revolução psicofarmacológica. À penicilina, que tratava efetivamente a sífilis, acrescentaram-se os neurolépticos e os antidepressivos, que transformavam os portadores das grandes psicoses em pacientes ambulatoriais. Mas tal avanço implicou outro problema: a assistência psiquiátrica pública se dividiu em duas: a assistência patrocinada pelo Estado e aquela mantida pela previdência social pública, que se multiplicou movida única ou predominantemente pela busca de lucro. O doente mental se transformou em uma fonte inesgotável de lucro para empresários que viviam dessa condição.

No plano da assistência pública direta, a tônica do enfrentamento desse problema residiu na tentativa de ambulatorização do tratamento. O Serviço Nacional de Doenças Mentais, desde a primeira gestão, do Professor Jurandyr Manfredini, encetou outra tentativa de reforma, elegendo como principal meta a substituição da hospitalização pela assistência ambulatorial. Nos anos 50 e 60 , esses recursos se multiplicaram, principalmente em unidades sanitárias e como anexos de hospitais psiquiátricos públicos. A principal crítica a esse sistema era a manutenção da segregação do enfermo e da enfermidade psiquiátrica, além dos cuidadores da rede de assistência. Os Colóquios de Psiquiatria Assistencial e Preventiva que se davam nos congressos da Associação Brasileira de Psiquiatria (ABP) e da Sociedade de Neurologia, Psiquiatria e Higiene Mental do Brasil testemunharam esse esforço, que não foi adiante porque o Estado Brasileiro era decididamente privatista nessa área. Por isso, na assistência previdenciária, o processo correu na direção oposta: a hospitalização foi priorizada unicamente porque era mais lucrativa para quem a promovia. Esse fato se refletiu na assistência pública direta, uma vez que se transformou em paradigma terapêutico na consciência social e na ideologia de muitos terapeutas. Deu-se também o fenômeno de transferência de pacientes desospitalizados na rede pública para serem internados em serviços credenciados pela previdência social pública. Essa situação foi muito agravada pela instituição da ditadura militar e pelo avanço ideológico neoliberalista, sobre o qual muito já foi relatado.

A Divisão Nacional de Saúde Mental (DINSAM), sob o comando de Hamilton Cerqueira, secundada pela ABP e apoiada nos organismos federais e estaduais, lideraram uma tentativa de reforma que colocasse o avanço técnico a serviço dos pacientes. Carlos Gari de Faria foi o componente gaúcho dessa tentativa, que iniciou um vigoroso processo de transformação responsável da assistência psiquiátrica.

Com a derrocada da ditadura, criaram-se condições para uma reação mais eficaz, não fosse pela divisão dos esforços reformistas. A reação à má assistência psiquiátrica se deu em três planos freqüentemente antagônicos: o plano médicopsiquiátrico, o plano antipsiquiátrico e o plano tecnocrático. A reação psiquiátrica foi realizada pela $\mathrm{ABP}$, a antipsiquiátrica foi encarnada por agentes de tendências anarquistas abrigadas no Partido dos Trabalhadores, e a reação burocrática esteve representada pelos dirigentes de serviços públicos e alguns agentes do chamado Movimento Sanitarista. 
Todos enfrentavam a poderosa Federação Brasileira de Hospitais, que sustentava a manutenção do quadro existente.

A ABP preparou um Projeto de Lei para estabelecer o que seria um Estatuto do Enfermo Psiquiátrico, que previa a desospitalização progressiva, à medida que fossem instalados serviços de cuidados primários (nas unidades sanitárias), secundários (nas policlínicas e hospitais gerais) e terciários (hospitais especializados e centros de habilitação e reabilitação), todos integrados na rede geral de assistência médica e social (integração que se considerava essencial para prevenir a discriminação e a exclusão).
Essa proposta foi atropelada pelo Projeto Paulo Delgado, fortemente apoiado, já de saída, pelos partidos de esquerda, por amplas camadas do movimento médico, pelo movimento sanitarista e pela burocracia sanitária federal. Os antipsiquiátricos responderam com esse projeto, de cunho atécnico e antimédico, que obstou a tramitação do plano da APB: passaram-se 10 anos até que o projeto fosse aprovado, e ainda assim quase inteiramente descaracterizado. Pode-se crer que os burocratas apoiaram o projeto anarquista porque ele era menos dispendioso e permitia que o poder federal repassasse o encargo para os municípios, livrando-se das responsabilidades que havia assumido desde 1930.

Aí acabam-se os primórdios e inicia a atualidade. 